\title{
Misunderstanding Discrimination of the Music Aesthetic Sensibility Cultivation of Primary and Secondary School Students
}

\author{
Dong-Ni SUN ${ }^{1}$, Ying-Ying XIAN ${ }^{2, b}$ \\ ${ }^{1}$ School of Art and Media, Bohai University, Jinzhou, China \\ ${ }^{2}$ School of Art and Media, Bohai University, Jinzhou, China \\ bxianyingying1980@126.com
}

Keywords: Music, Aesthetic Education, Aesthetic Sensibility

\begin{abstract}
Nowadays, the primary and secondary school aesthetic experience of music education in our country focuses more on interests of students and experience, etc, it is no longer single imparting education. However, some problems, such as the cultivation methods or ways of the music aesthetic experience of primary and secondary school students can not be very accurately positioned. This paper makes analysis from three aspects: first, the purpose of aesthetic education is to improve the aesthetic experience ability and enhance musical aesthetic sensibility; second, the basic knowledge of music is the basis of music aesthetic sensibility training; third, balanced selection of western music and Chinese folk music in the music aesthetic sensibility training. It is necessary to study the diversity of the music, and learn the blending of excellent music culture, so as achieve real purpose of musical aesthetic sensibility training, and ultimately achieve the value of music aesthetic experience education on "people".

With the continuous development of musical art education of primary and secondary school in China, which has experience several years of exploration and practice, it establishes the essential characteristics and connotation with the core of musical aesthetic education in trial and error, thus making significant progress in the study and life of the art of music in primary and secondary schools. Since the implementation of the new curriculum standard, the music education of primary and secondary students has broken the previous situation with musical knowledge and skill as the main part of musical art study, to put emphasis on the life, interests, need, experience and feelings of primary and secondary students, paying more attention to training students of their music aesthetic sensibility and emotional experience of primary and secondary students. "It starts from a practical art education of children, to pursue the creation of meaning, nourish life, and contribute to the growth.”At present, although educators have found the direction of musical art education of primary and secondary students-with the cultivation of students' music aesthetic sensibility as the core, there is still a problem in the implementation of music education, namely "music education should achieve its aesthetic education characteristics" this goal of music study should become the so called slogan, however, to reach the access point of musical aesthetic education, the methods and approaches are always vague or inaccurate, and then, music aesthetic education will be useless and beyond reach, and it will also be meaningless to study. To solve the existing problems, the first should be done is to develop students' music sensibility. The music not only has fluid lines, but also it is the art of hearing, only with a large amount of listening, can students obtain certain auditory sensibility of music. Only with a touch in the sensibility nerve of hearing, will students resonate with the music, so that the student will instinctively want to have a great increase in music, and their own imagination, creativity, understanding of aesthetics, appreciation ability and interests in and desire for music will be further improved. Throughout the study of musical aesthetic experience, in addition to listening, basic knowledge and skills of music should be added in, in this ways, the study and mastery of musical knowledge will lay a solid foundation for the musical aesthetic ability, to a certain extent, which will motivate students to release their musical emotion and energy, so that students can continuously improve their music aesthetic sensibility during study and deepen musical appreciation ability to give students a pair of ears to appreciate and feel music, and pure soul, to gradually become excellent people that are good at music appreciation and feeling. Thus, it can be seen that the cultivation of
\end{abstract}


music aesthetics education should be acquired through study and increase of music aesthetic sensibility. Music aesthetic sensibility is the foundation of music education to achieve aesthetic education.

\section{First, the Purpose of Aesthetic Education is to Improve the Aesthetic Experience Ability and Enhance Musical Aesthetic Sensibility}

School should make the most effort to train the aesthetic sensibility of musical art of each student. In the reform, it continues to put forward to make music aesthetics as the core, interests as the driving force, students as the subject in music class, and teachers as the object to assist students to study in class, teachers should lead students to experience the beauty, feel the beauty and appreciate the beauty, to stimulate students' interest in music study, and cultivate students' ability of discovering the beauty, feeling and appreciating the beauty to become good at aesthetic.

The aesthetic experience of students got in singing "Little Star" is the same with that of musicologist and experts when immersing in "Beethoven's Ninth", only in different degrees. The task of aesthetic education is to influence such a degree, and to enhance students' ability of aesthetic experience and their aesthetic sensibility.

In the musical aesthetic experience study, teachers should enlighten students profoundly, and give students space to have deep thinking. In the music classes in primary and secondary schools, teachers often ask firstly before playing music: Do you like this music? Do you like the singing of this singer? A music teacher should know that the cultivation of aesthetic experience ability of students is not to make judgments on the likes and dislikes of music or musical performances, but to make aesthetic observation and reflection and reflection of the expressive force of music, which is a creative experience, and ultimately improves students' aesthetic sense, thus making the music education become aesthetic education.

In the classroom teaching, students are the subject, and teachers play a leading role. The process of music aesthetics is that teachers help students to discover the beauty, feel the beauty and create the beauty. In the music aesthetic learning process, the dominant role of students should be adhere to, and teachers just need to give some guidelines, such as the creative background of musical works, understanding of composers, analysis of modal tonality, mastering of the structure of music, etc. Never to over-dominate students' feeling and experience of musical works, nor make some subjective presentations, because the music itself is subjective, and also it has extensive space for imagination. "There are a thousand Hamlets in a thousand people's eyes", musical aesthetic is also the same ."Aesthetic experience education of music is to enable students to continue to dedicate themselves to a particular educational environment in the classroom, to make their souls be close to the music and they can feel the music to the greatest extent." ${ }^{3}$ But now there are problems that many teachers think it better to make the music presentation more detailed, and students can be more clearly about it. However, it is not the case, music is not mathematics or Chinese, it is a departure from the musical aesthetic rule, straying from the original intention of musical aesthetic sense. Music aesthetics education should focus on the musicality in musical education and emphasize the aesthetic experience of music education. Therefore, "in educational practice, the attribution of music aesthetic should be followed, and the dominant position of students should be respected, so that students can experience and participate in the music naturally and actively in the aesthetic environment of music, enhance music aesthetic ability, and ultimately achieve the music education of the people” (4)

Teachers should also constantly improve their aesthetic ability in teaching, to improve students' aesthetic level, as well as themselves. Students can participate in the play or interact with teachers in musical communication, so that students can personally experience the feeling of the music which is different from the music in electronic players, at the same time, it stimulates students' interests and curiosity in music aesthetic experience, to help students to cultivate and explore their own aesthetic experience and aesthetic ability from different channels and in various ways. Students can also make relative evaluation of some relatively simple music works students with relevant knowledge they 
have learned, and the teacher can offer some suggestions, to provide musical education in widespread, deep and musical understanding method.

\section{Second, the Basic Knowledge of Music is the Basic of Music Aesthetic Sensibility Training}

"Basic knowledge of music and study of basic skill should organically permeates the aesthetic experience of musical art". 5 Therefore, in the process of teaching music aesthetic experience, study of the basis knowledge of music aesthetics, namely foundation skill of musical aesthetic is also vital. Musical aesthetic education is actually the same with the education of other subjects, all requiring a certain amount of theoretical basis, which is the important condition and foundation to master the experience ability. At this stage, although the musical aesthetic education advocate stressing the aesthetic training, it does not mean to ignore the understanding and learning of music aesthetic skills. Although the study of basic knowledge of music aesthetics is not the precondition for students to participate in music aesthetics experience, the aesthetic ability is indeed an important power to guarantee students' music aesthetics activities and improve students' aesthetic ability. Many examples show that there always phenomenon in the music aesthetic class of primary and secondary school that after playing the music, many students only think about whether or not the music is pleasant to hear, and teachers only ask shallow questions while not think deeply, which lies in the lack of basic music aesthetic skills, making it impossible to obtain a deeper level of joy and pleasure of music aesthetic. It indicates that study and master of music aesthetic skills occupy a certain proportion in developing music aesthetic sensibility, and educators should balance both of them well. A good knowledge of music aesthetic skills is the basis, only with certain basic knowledge of music aesthetic, can the music aesthetics experience ability be obtained to make big process. But, music teachers are prone to care too much about the skills and tools of music activities, to experience the music, and less enough "psychological distance" experience the music. Educators should provide aesthetic education to students, but not make music training simply, however the study of music aesthetics is the basic of the formation of music aesthetic feeling ability. Therefore, when students are experience music aesthetic sensibility, basic knowledge of music should be given properly, for example learning some basic theoretical knowledge of music, experiencing the rhythm of the music, singing the main melody of the song and so on, These are the most basic knowledge and skills of learning music, and also the basic link of music aesthetic sensibility training. In the music aesthetic classes of primary and secondary school, we often find that music teacher will teach a lot of basic knowledge of music in one class, and the effect is often not unsatisfactory, students tend to feel boring and loss the passion and excitement at the beginning, and have no aesthetic feeling about music. In the analysis, communication and experience of music, teachers should focus on the method and language of musical representation, to eliminate barriers between the student and music, not impose subjective opinions on the music, and master the relation between the basic skills and feelings of music aesthetics. So, teachers should be based on the music aesthetics experience of students, to insert the basic knowledge and skills of music, aesthetics into the music aesthetics experience, which not only makes students to learn certain music aesthetics knowledge in limited teaching time, but also relieve the boring feeling of study, to make students spend class time easily in the process of music aesthetic experience and feel the charm of music. The music exists all the time, in class, the teacher lead the students to study the music aesthetic sensibility, and then in their spare time, primary and secondary school students are in the golden period of learning knowledge. If students can study or master a specialty in the spare time, such as, vocal music, instrumental music, dance, etc, it will be of considerable help to improve their music aesthetic ability. Primary and secondary students personally practice feel the rhythm of music, and participate in the play, to have direct communication with the music, causing more intense collision on the mind, thus producing the inner music flowing, students can strengthen the training of music aesthetic skills in the self music communication process, and also know about and think about music in a rational level, to get emotional sublimation and release of the soul, to really feel the music in life. It also help students to improve the music .appreciation ability, so that students' emotional feeling can be met further in the music. Nowadays, the training of artistic 
experience education of primary and secondary school has indeed been significantly improved. In recent years, the teaching concept on students' music aesthetic training has changed greatly, and some musical teachers can turn the concept into educational behavior. But some teachers may lack knowledge and skills, and have single ideology structures. It is difficult for them to change that concept into behaviors. Therefore, the strengthening of the learning degree still takes time in the education and cultivation of music aesthetic sensibility of primary and secondary students.

\section{Third, Balanced Use of Western Music and Chinese Folk Music in the Music Aesthetic Sensibility Training}

In the class of music aesthetic experience education cultivation of primary and secondary school students, teachers often will choose works of some famous European music masters from start to the end of the whole entire chapter for the students to enjoy, such as Mozart, Beethoven, Chopin. It is always that in the primary and secondary school music classes, the music of European masters are appreciated most, and Chinese musical works only account for a small part, from which it can be seen clearly that many teachers think the music of European masters are more elegant, and profound, and that listening to Western symphony, opera and other music can improve the level of aesthetic feeling of the students. But the feedback of students' aesthetic results are often unsatisfactory. It is undeniable that such Western music can really enhance students' musical aesthetic cultivation at a higher level and improve the ability of music aesthetic experience. But the musicality of European classical music is strong, it requires good music accomplishment and culture deposits to enjoy this kind of music. But primary and secondary school students are just beginners, whose accumulation of knowledge in music is not enough, and it is difficult for them to understand, so that they are not able to fully feel its beauty, or understand the classical music completely.

The appreciation of Chinese music works should also not be ignored, and they should also select some excellent works for the students to appreciate. Chinese folk music has various types, styles and varieties, which are shown in the form of songs, as well as having their own outstanding opera works with their national styles, such as The White Haired Girl, Mourning, CangYuan, etc. Although it is not so magnificent as the Western music in orchestration, its ethnic and cultural characteristics are very prominent. Play excellent music work of different ethnic groups in the music aesthetic experience lesson, through continuous appreciation, feelings and experience, to enable students to know various ethnic music gradually and fell in love with it. Through continuous study of the Western music and Chinese music, it can ensure students' diversified development of musical aesthetic experience, to achieve double-footed effect. It can not only improve the diversified development of students for the music aesthetic ability, but also inherits and develops Chinese musical culture well.

The training of music aesthetic sensibility requires accumulation, only when the aesthetic ability reaches a certain level, will there be a qualitative progress in the aesthetic experience. In the process of experience teaching, whether it is Western music or Chinese music, in order to prevent the students from feeling bored because of tedious and lengthy work, teachers can select a part or a piece of music works for the students to enjoy, feel and experience, and students can make analysis and evaluation with their knowledge of music, to put forward their views and discuss about it with teachers. At this time, teachers can also give appropriate guidance, from shallow to deep, from easy to difficult, to make students gradually experience the emotion excitation brought by different music cultures, to have deeper aesthetic feelings. Thereby, it can really start from students'own feelings, for them to enjoy the endless charm of the music, feel the diversity of the music world, and ultimately achieve the purpose of music aesthetic sensibility education.

\section{References}

[1] Renmei Wang, Study on the Historical Evolution of Chinese Pre-school Children Art Education Since the Reform and Opening up, Nanjing Normal University doctoral dissertation. (2012) 
[2] Yunhong Peng, On the Training of Music Aesthetic Sensibility, Arts Education.

Reference to a book:

[3] Ming Ji, Analysis and Practice of the Fundamental Philosophy of Music Course "With Musical Aesthetics as the Core”, Shenyang Normal University, master’s thesis. (2013).

[4] Chen Du, Consideration and Cognition on "With Musical Aesthetics as the Core"-based on "Philosophy of Music Education” written by Ramo, Southwest University master’s thesis (2010)

[5] Keni Sun, Implementation of Aesthetic Function in Middle School Music Teaching, Northeast Normal University, master's thesis. (2007) 